\section{Analysis of foreign matter in foodstuffs using the light filth test: report 2012-2013}

\author{
Maria Giovanna Tilocca, ${ }^{1}$ Elisa Caneglias, ${ }^{1}$ \\ Bruna Vodret, ${ }^{1}$ Maria Rosalba Mancuso, ${ }^{1}$ \\ Antonina Zimmardi, ${ }^{2}$ Claudia Manno, ${ }^{2}$ \\ Maria Rita Schiavo² \\ 'Food Hygiene Unit, Institute for \\ Experimental Veterinary \\ Medicine of Sardinia, Sassari; \\ 2Specialized Diagnostic Unit, Institute \\ for Experimental Veterinary Medicine \\ of Sicily, Palermo, Italy
}

\begin{abstract}
The European legislation set the new hygiene standards in food chain with the purpose to ensure high levels of public health protection in relation to food production. In order to guarantee excellent hygiene standards in food chain, particular attention must be paid to the presence of foreign matter, like light solid impurities of mineral, vegetable or animal origin. The light filth test is a suitable method used to detect and count light solid impurities applicable to different foodstuffs. We report the results of the analysis of 93 foodstuffs official samples investigated for the presence of foreign matter at the Institute for Experimental Veterinary Medicine of Sardinia, from 2012 to 2013. Insect fragments were found in a sample of semolina and in a sample of canned tomato; plastic fragments were found in a sample of grated bread.
\end{abstract}

\section{Introduction}

Analysis for extraneous matter (or solid impurities) is important both in selecting of raw material for food manufacturing and in monitoring the quality of processed foods. The presence of extraneous material in food products is unpleasant and can cause a serious health hazard to the consumer. The main reason for carrying out analyses for extraneous matter in food is to ensure the protection of consumers from harmful or filthy food products. The analysis of filth test allows to detect and count light solid impurities of mineral, vegetable or animal origin, and gives information about food preparation, conservation and distribution too. The light-filth method pays particular attention to extraneous particles contaminating food (such as insects, insect fragments, rodent or other mammals hairs, human hairs, feather barbules, carbonaceous particles, natural and synthetic fibres), extending to the identification of the material from which they have originated, animals or vegetables. The analysis is applicable to cereals and by-products (flours, pasta and bakery products), fresh and conserved vegetables, spices, coffee, cocoa, milk and by-products, mushrooms and so on.

The Federal Food, Drug and Cosmetic Act of the 1938 with Amendments administered and enforced by the US Food and Drug Administration (FDA) defines food as adulterated if it consists in whole or in part of any filthy, putrid, or decomposed substance, or if it is otherwise unfit for food (21 U.S. Code \$342, Section 402 - Adulterated food (a)(3)); or if it is as been prepared, packed, or held under unsanitary conditions whereby it may have been rendered injurious to health (21 U.S. Code $\S 342$, Section 402 - Adulterated food (a)(4)) (FDLI, 1993). The only Italian regulation in force is Law No. 283/1962: it is forbidden the use, the sale, the possession for sale, the administration as a reward and the distribution for consumption of food substances filthy and invaded by parasites, represent a violation provided by letter d) of Article 5 of Law No. 283/1962 (Italian Republic, 1962).

The European Community's food and feed hygiene legislation, called The Hygiene Package (mainly the EC Regulation 852/2004, 853/2004, 854/2004 and 882/2004; European Commission, 2004a, 20014b, 2004c, 2004d) came into effect across all Member States from $1^{\text {th }}$ January 2006. The Hygiene Package revises and consolidates legislation in relation to food and feed hygiene along with the production, control and marketing of products of animal origin and animal health issues in relation to the production of those products. The Hygiene Package was motivated by the necessity to ensure high levels of public health protection in relation to food production. Therefore, the European food industry was encouraged to improve the hygienic standard in food production with respect to both nutritional characteristics and hygienic-sanitary aspects (Trematerra, 2011, 2013; Canale, 2014).

However, Rapid Alert System for Food and Feed (RASFF), in 2012 annual report, has notified 24 alerst, 61 border rejections, 26 pieces of information for attention, 47 pieces of information for follow up in hazard category foreign bodies (RASFF, 2012).

The Food Hygiene Department of Institute for Experimental Veterinary Medicine of Sardinia works on official food controls analysis, in the Regional Control Program named Plan and interventions coordination for official control of food. Program 2012-2014 to protect the public from harmful or filthy food products in accordance with European Regulation.

Our study shows the results of the
Correspondence: Maria Giovanna Tilocca, Food Hygiene Unit, Institute for Experimental Veterinary Medicine of Sardinia, via Vienna 2, 07100 Sassari, Italy.

Tel: +39.079.2892332 - Fax: +39.079 .2892324$

E-mail: mgtilocca@gmail.com

Key words: Light filth test, Insect fragments, Plastic fragments, Foodstuff.

Received for publication: 7 July 2014.

Revision received: 12 November 2014

Accepted for publication: 13 November 2014.

This work is licensed under a Creative Commons Attribution 3.0 License (by-nc 3.0).

(C) Copyright M.G. Tilocca et al., 2015

Licensee PAGEPress, Italy

Italian Journal of Food Safety 2015; 4:4504

doi:10.4081/ijfs.2015.4504

analysis of foodstuffs for the presence of extraneous matter using the light filth test from 2012 to 2013.

\section{Materials and Methods}

A total of 93 foodstuff official samples were investigated for the presence of foreign matter using light filth test from 2012 to 2013; details of the samples analysed are as shown in Table 1. The light filth test analysis was carried out using official methods and in-house protocols. Solid impurities from flour and transformed products were isolated, identified and analysed using the official light filth method as described in the Italian Agricultural Policy Ministry (Italian Republic, 1999). Filth test in tomato products, fresh and conserved vegetables, coffee, spices, soft drinks was carried out using official methods of analysis of the Association of Official Analytical Chemists (AOAC, 2012) by floating; dietary food products (whole-wheat cereal), baby food (dry infant cereals), and sugar were analysed using inhouse protocol by sieving (Table 1). The extraneous material was filtered onto ruled filter paper for microscopic examination.

\section{Results}

The results highlighted the presence of extraneous matter in two different kinds of food matrix, in flour-products and in canned tomatoes. Insect fragments were found in a sample of semolina and in a sample of canned tomatoes (Figure 1), while plastic fragments were found in grated bread (Figure 2). 


\section{Discussion}

In the US, the FDA has set defect action levels as the regulatory standard for quality control (FDA, 2011). For insect contamination, the defect action level is 75 insect fragments per $50 \mathrm{~g}$ of wheat flour. In tomato products, the defect action level set is the average of 10 or more fly eggs per $500 \mathrm{~g}$; or 5 or more fly eggs and 1 or more maggots per $500 \mathrm{~g}$; or 2 or more maggots per $500 \mathrm{~g}$ (FDA, 2011).

It should be noted that the Italian regulation, although not referring to the number of insect fragments, is very restrictive to infested products with zero tolerance (Italian Republic, 1962). The analysis of foodstuffs for the presence of foreign matter from 2012 to 2013 showed how in the Regional Control Program three samples were resulted non-compliant with national regulatory requirements. The presence of insect fragments in semolina and tomato-products suggests a possible contamination from the field, or contamination during the storage of products and finally as contamination during products processing, while the presence of plastic fragments in grated bread suggests a possible contamination during the packaging.

\section{Conclusions}

In conclusion, although the Regional Control Program includes different food matrices, it would be necessary to extend the light filth test to other categories of foodstuffs and simultaneously increase the number of samples in order to safeguard the health of consumers and to guarantee the correct application of the law.

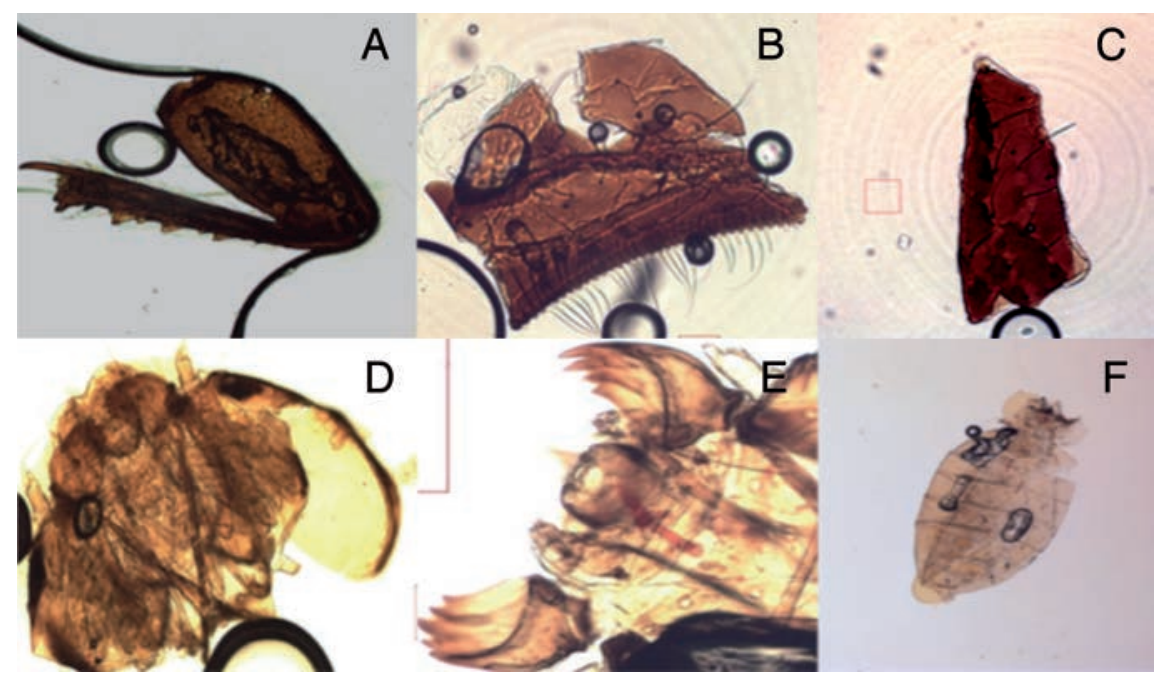

Figure 1. Insect fragments detected in semolina $(\mathrm{A}, \mathrm{B}, \mathrm{C})$ and in canned tomatoes $(\mathrm{D}, \mathrm{E}$, F).

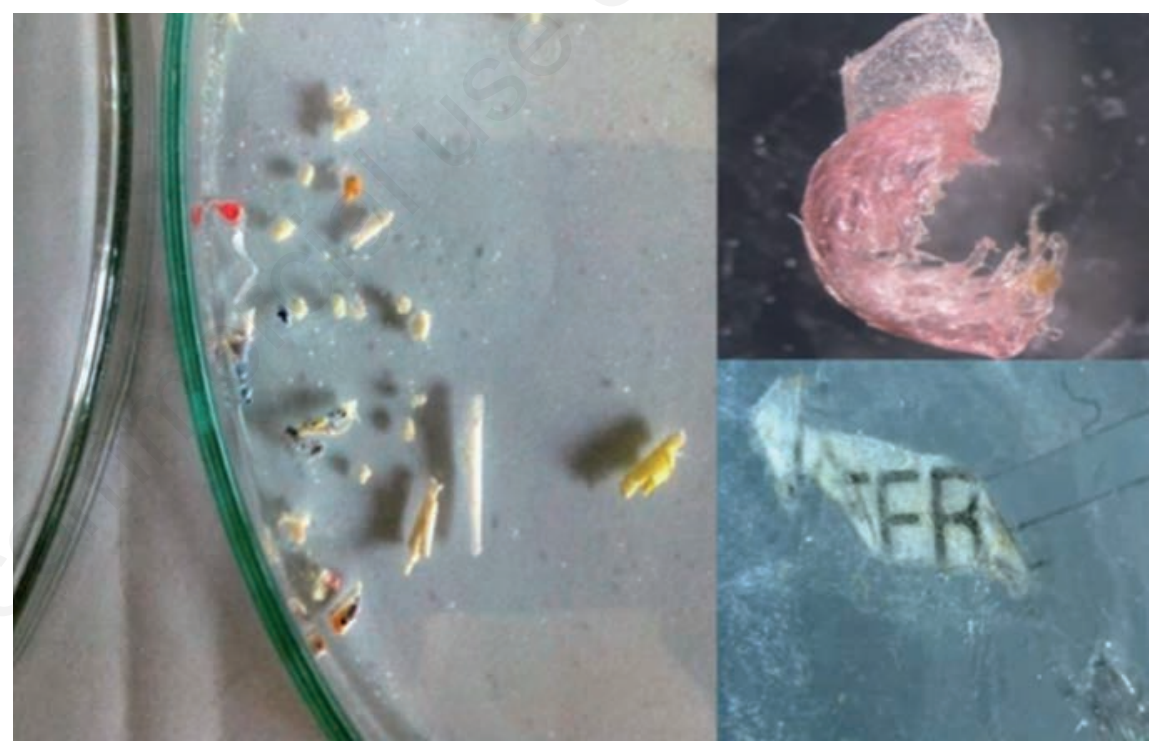

Figure 2. Plastic fragments detected in grated bread.

Table 1. Foodstuffs investigated using light filth methods.

\begin{tabular}{|c|c|c|c|c|}
\hline Food products & Number of & Light filth test & Numbe of positive samples & Foreign material detected \\
\hline Flour and transformed products & 59 & $\begin{array}{l}\text { Official method of analysis for cereals } \\
\text { (Italian Republic, 1999) }\end{array}$ & 2 & Insect/plastic fragments \\
\hline Fresh and conserved vegetables & 12 & AOAC $974.33(\mathrm{AOAC}, 1974)$ & - & - \\
\hline Coffee & 8 & AOAC 988.16 (AOAC, 1988d) & - & - \\
\hline Tomato products & 6 & AOAC 955.46 B (AOAC, 1988a) & 1 & Insect fragments \\
\hline Spices & 3 & AOAC 977.25 B (AOAC, 1988c) & - & - \\
\hline Soft drinks & 2 & AOAC 970.72 B (AOAC, 1988b) & - & - \\
\hline Dietary food products & 1 & In-house protocol & - & - \\
\hline Baby food & 1 & In-house protocol & - & - \\
\hline Sugar & 1 & In-house protocol & - & - \\
\hline
\end{tabular}


stuffs, 852/2004/EC. In: Official Journal, L 139/1, 30/04/2004.

European Commission, 2004b. Regulation of the European Parliament and of the council of 29 April 2004 laying down specific hygiene rules for on the hygiene of foodstuffs, 853/2004/EC. In: Official Journal, L 139/55, 30/04/2004.

European Commission, 2004c. Regulation of the European Parliament and of the Council of 29 April 2004 laying down specific rules for the organisation of official controls on products of animal origin intended for human consumption, 854/2004/EC. In: Official Journal, L 139, $30 / 04 / 2004$.

European Commission, 2004d. Regulation of the European Parliament and of the Council of 29 April 2004 on official controls performed to ensure the verification of compliance with feed and food law, animal health and animal welfare rules, 824/2004/EC. In: Official Journal, L 165, $30 / 04 / 2004$.

FDA, 2011. Defect levels handbook. The food defect action levels e levels of natural or unavoidable defects in foods that present no health hazards for humans. Food and Drug Administration ed., Silver Spring, MD, USA. Available from: http://www.fda.gov/food/guidanceregulation/guidancedocumentsregulatoryinformation/sanitationtransportation/ucm0561 74.htm

FDLI, 1993. Federal food drug and cosmetic act, as amended. DC. 21 U.S. Code $\S 342$, Section 402 - Adulterated food (a) 3-4. In compilation of food and drug laws. The Food and Drug Law Institute, Washington, DC, USA.

Italian Republic, 1962. Legge del 30 Aprile 1962. Disciplina igienica della produzione e della vendita delle sostanze alimentari e delle bevande, n. 283. In: Official Journal, L 139, 4/06/1962.

Italian Republic, 1999. Metodi Ufficiali di analisi dei cereali "Determinazione delle impurità solide (Filth-test) negli sfarinati e nei prodotti di trasformazione" e "Identificazione di sostanze di origine biologica e di sostanze estranee minerali negli sfarinati di cereali". In: Official Journal, L 64, 18/03/1999, Suppl. $\mathrm{n}^{\circ} 5$. Available (in Italian) from: http://www.gazzettaufficiale.it/eli/id/1999/0 3/18/099A1923/sg

RASFF, 2012. The Rapid Alert System for Food and Feed 2012. Annual report. Available from: ec.europa.eu/food/safety/rasff/docs/ rasff_annual_report_2012_en.pdf

Trematerra P, Stejskal V, Hubert J, 2011. The monitoring of semolina contamination by insect fragments using the light filth method in an Italian mill. Food Control 22:1021-6.

Trematerra P, Stejskal V, Hubert J, 2013. Aspects related to decision support tools and integrated pest management in food chains. Food Control 34:733-42. 